\title{
Spontaneous healing of traumatic perforations of the tympanic membrane
}

\author{
Salim H. Al-Obiedi \\ Department of Surgery, College of Medicine, Tikrit University.
}

(Ann. Coll. Med. Mosul 2009; 35(1): 26-32).

Received: $25^{\text {th }}$ May 2008; Accepted: $25^{\text {th }}$ Jan 2009.

\begin{abstract}
Objective: To study the spontaneous healing of various types of traumatic perforations of the tympanic membrane in a prospective study carried out on patients with traumatic perforations of the tympanic membrane, presented to same author.

Methods: Eighty patients with 84 traumatic perforations of the tympanic membrane were studied at Tikrit Teaching Hospital, during the period from Jan. to Dec. 2007. Diagnosis made by a history of trauma and otoscopic examination. Antibiotics were given to prevent or treat infections. Advice to keep the ear dry. Follow up the patients for a minimum of six months.

Results: The male: female ratio was (2.6:1). Left ear perforation was more than right ear, (5\%) were bilateral. The commonest cause was blast injury in 34 patients $(43 \%)$, then hand slap in 22 patients (27.5\%). The age of the patients was from 4-65 years, common age group affected was (21-30 years), they were 39 patients (49\%). Spontaneous healing occurred in 69 cases (82\%), persistent dry perforation in 8 cases $(9.5 \%)$, and 7 cases $(8.5 \%)$ ended with chronic suppurative otitis media. Fiftysix cases $(81 \%)$ got complete healing within six weeks. All cases due to fractures of temporal bone got spontaneous healing $(100 \%)$, then perforation by foreign body and instrumentation $(89 \%)$, ear syringing, and hand slap was equal $(88 \%)$, then due to ear suction $(80 \%)$, and the lower incidence in blast injury were (75\%). Healing of posterior and anterior perforations about equal $(92 \%),(91 \%)$ respectively, then kidney shape perforation $(85 \%)$, but none of 7 cases of subtotal perforations healed spontaneously.

Conclusion: Conservative care for traumatic perforations of the tympanic membrane gives excellent chance for spontaneous healing. The factors affecting spontaneous healing include, large size perforations, ear infections, type of trauma, and Eustachian tube dysfunction.
\end{abstract}

Keywords: Traumatic perforation; tympanic membrane; spontaneous healing.

الخلاصة

الهـدف: در اسة الاندمال التلقائي (الذاتي) لأنواع مختلفة من الثقوب الرضية في طبلة الأذن.

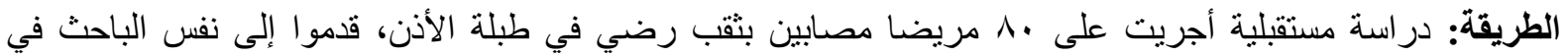

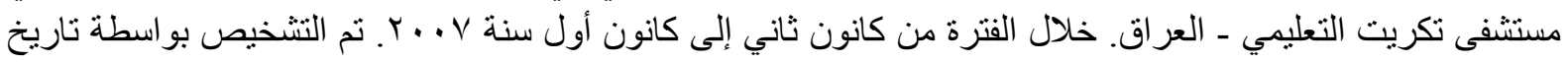

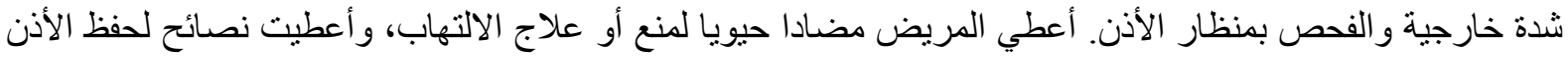

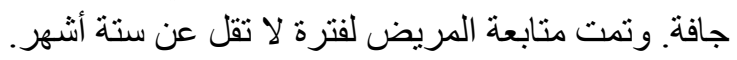

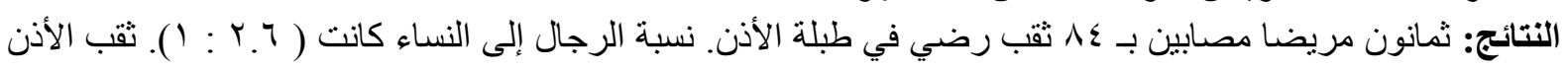

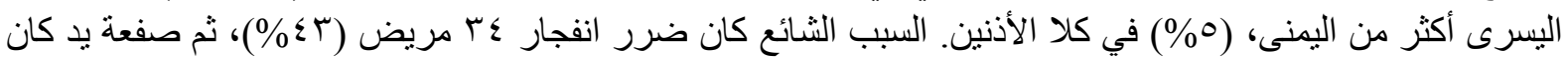

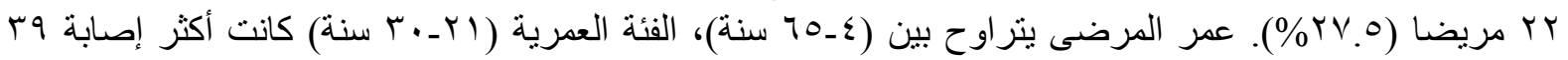

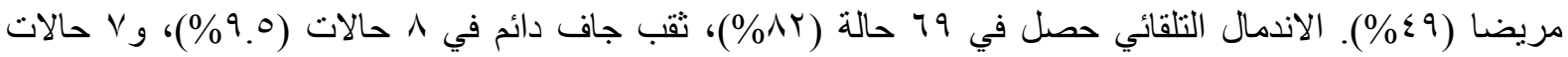




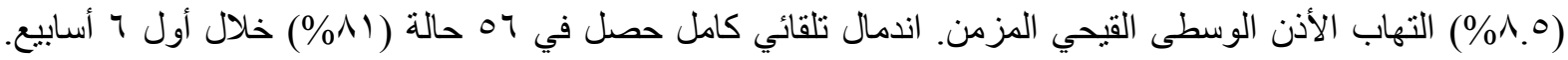

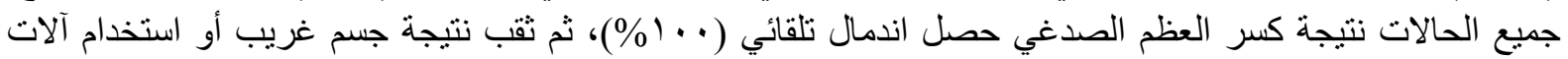

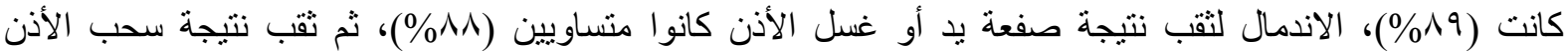

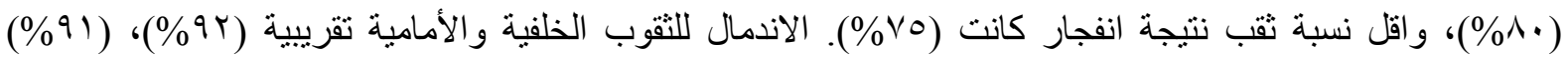

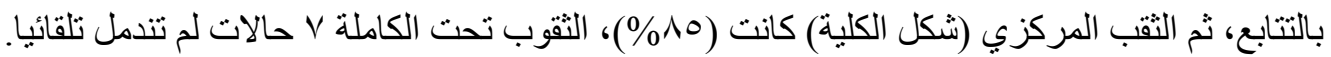
الاستتتاج: العناية الوقائية للثقب الرضي في طبلة الأذن بعطي حظ ممتاز للاندمال التلقائي (الذاتي). العو امل المؤثرة على لألى

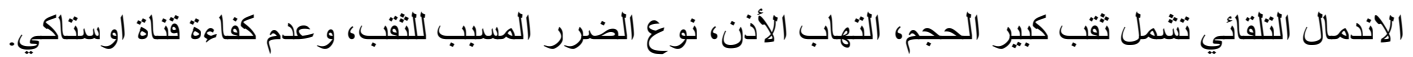

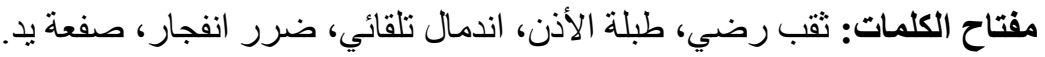

T he tympanic membrane is a thin wall that separates the outer ear from the middle ear $^{(1)}$. It is much more traumatized than middle or inner ear $^{(2)}$. The incidence has been estimated at 6.8 per 1000 person $^{(3)}$, and the annual incidence rates of traumatic perforation vary between 1.4 to 8.6 per $100.000^{(2)}$. The causes of acute rupture of tympanic membrane, include direct trauma by instruments such as cotton swab, pin, and sticks; welding; skull fracture; foreign body. latrogenic like syringing, suction, and probing of the ear. Pressure changes include blast injury, open palm trauma (slapping), diving, and flying ${ }^{(4)}$.

Most of isolated traumatic perforations of the tympanic membrane can be managed with conservative care. The ear should be kept clean and dry while the ear drum heals; insertion of cotton ball with Vaseline into the ear when showering or bathing, avoid blowing the nose, as the pressure created when blowing the nose can damage healing ear drum tissue, and causes infection ${ }^{(1)}$.

Surgical repair includes myringoplasty, tympanoplasty, and ossiculoplasty, which are indicated if it does not heal by itself, for 3-6 months especially if associated with significant conductive hearing loss, and recurrent drainage ${ }^{(4)}$.

\section{Patients and methods}

This is a prospective study which was carried out on patients presented to the author with traumatic perforations of the tympanic membrane, at Tikrit Teaching Hospital, during the period from Jan. to Dec. 2007.

They were 80 patients. Questioning included type and duration of trauma, presence of otalgia, otorrhea, vertigo, hearing loss, tinnitus. Physical examination: Inspection of the auricle for any sign of trauma, palpation for tenderness, careful suctioning of blood, purulent discharge, and debris, from the ear canal if present. Diagnosis made by otoscopic examination; shape, size and location of the perforation \{posterior, anterior, central (kidney shape) or subtotal\} were recorded. Tuning fork tests (Renne's, Weber's, and Absolute bone conduction test.). The ear should be kept dry.

An antibiotic was used to prevent or treat infection. Oral Amoxicillin + clavulanic acid 375 $\mathrm{mg} / \mathrm{t}$.i.d/ for seven days, or according to $\mathrm{C} / \mathrm{S}$ test. Aural toilet was done when indicated.

Advice to weekly follow up was given to the patient if he has pain or swelling in the ear or discharge from his ear. Follow up period was for a minimum of six months.

\section{Results}

Eighty patients, with 84 traumatic perforations of the tympanic membrane; 58 patients $(72.5 \%)$ were males, and 22 patients $(27.5 \%)$ were females. (M:F ratio 2.6:1) (Figure 1). Left ear perforations were 52 patients $(65 \%)$, right ear were 24 patients $(30 \%)$, and 4 patients $(5 \%)$ with bilateral perforations. Explosive blast injury of the ear was the commonest cause, 34 patients $(43 \%)$, hand slap 22 patients $(27.5 \%)$, then foreign body and instrumentation 9 patients (11\%), ear syringing 8 patients $(10 \%)$, ear suction 5 patients $(6 \%)$, and fracture temporal bone 2 patients $(2.5 \%)$.

The common age group affected was (21-30 year), 39 patients $(49 \%), 25$ patients $(54 \%)$ were due to blast injuries. Hand slap was the commonest cause in the age group (11-20 year) were 8 patients $(47 \%)$, while the foreign 
bodies and instrumentation were the commonest causes of the perforation in the age group ( $\leq 10$ years), 6 patients (75\%) (Figure 2).

The commonest site of traumatic perforation of tympanic membrane was posterior perforation which were 45 cases $(54 \%)$, then central (kidney shape) were 20 cases $(24 \%)$, then anterior perforation were 12 cases $(14 \%)$, then subtotal perforation were 7 cases $(8 \%)$ (six due to blast injury, and one due to foreign body button battery (Table 1 ).

From 84 perforated tympanic membranes, in 69 cases $(82 \%)$ the spontaneous healing occurred, 8 cases $(9.5 \%)$ got dry perforation with normal middle ear mucosa, and 7 cases $(8.5 \%)$ having active chronic suppurative otitis media. (Table 2).

Spontaneous healing of perforation due to fracture of temporal bone was (100\%), then foreign body and instrumentation, ear syringing, and hand slap were (89\%) (88\%) $(88 \%)$ respectively. Perforations due to ear suction was $(80 \%)$, blast injury was $(75 \%)$ (Table 2).

Spontaneous healing of posterior and anterior perforation was about equal (92\%), $(91 \%)$ respectively; for central (kidney shape) perforation was $(85 \%)$, but none of seven cases with subtotal perforation got spontaneous healing, four cases with continuous otorrhea ( chronic suppurative otitis media), and three cases ended with dry perforation during the follow up period (Table $3)$.

The duration of complete spontaneous healing was within 2 weeks in eleven cases $(16 \%), 27$ cases $(39 \%)$ healed within 4 weeks, 18 cases $(26 \%)$ healed within 6 weeks, and 13 cases $(19 \%)$ healed within more than 6 weeks, so $(81 \%)$ healed spontaneously within the first six weeks (Table 4).

Table (1): The site and size of traumatic perforation

\begin{tabular}{|l|c|c|c|c|c|c|c||}
\hline \multicolumn{1}{|c|}{$\begin{array}{c}\text { Site of the } \\
\text { perforation.* }\end{array}$} & Total & $\begin{array}{c}\text { Blast } \\
\text { injuries }\end{array}$ & Hand slap & $\begin{array}{c}\text { Foreign } \\
\text { body }\end{array}$ & $\begin{array}{c}\text { Ear } \\
\text { syringing }\end{array}$ & $\begin{array}{c}\text { Ear } \\
\text { suction }\end{array}$ & $\begin{array}{c}\text { Fracture } \\
\text { temporal } \\
\text { bone }\end{array}$ \\
\hline \hline Posterior & $45(54 \%)$ & $19(42 \%)$ & $16(36 \%)$ & $3(6.6 \%)$ & $3(6.6 \%)$ & $2(4.4 \%)$ & $2(4.4 \%)$ \\
\hline Anterior & $12(14 \%)$ & $5(42 \%)$ & $4(33 \%)$ & $1(8 \%)$ & 0 & $2(17 \%)$ & 0 \\
\hline $\begin{array}{l}\text { Central (kidney } \\
\text { shape) }\end{array}$ & $20(24 \%)$ & $6(30 \%)$ & $4(20 \%)$ & $4(20 \%)$ & $5(25 \%)$ & $1(5 \%)$ & 0 \\
\hline Sub total & $7(8 \%)$ & $6(86 \%)$ & 0 & $1(14 \%)$ & 0 & 0 & 0 \\
\hline Total & $84(100 \%)$ & $36(43 \%)$ & $24(28.5 \%)$ & $9(11 \%)$ & $8(9.5 \%)$ & $5(6 \%)$ & $2(2 \%)$ \\
\hline
\end{tabular}

*No attic or marginal perforations were reported.

Table (2): Sequelae of the traumatic perforation of the tympanic membrane

\begin{tabular}{||l|c|c|c|c||}
\hline \multicolumn{1}{|c|}{ Type of trauma } & No. Perforated T.M & Healed & Dry perforation. & CSOM (active) \\
\hline \hline Blast injury. & 36 & $27(75 \%)$ & $6(17 \%)$ & $3(8 \%)$ \\
\hline Hand slap & 24 & $21(88 \%)$ & $2(8 \%)$ & $1(4 \%)$ \\
\hline Foreign body. & 9 & $8(89 \%)$ & 0 & $1(11 \%)$ \\
\hline Ear syringing. & 8 & $7(88 \%)$ & 0 & $1(12 \%)$ \\
\hline Ear suction. & 5 & $4(80 \%)$ & 0 & $1(20 \%)$ \\
\hline Fracture temporal bone & 2 & $2(100 \%)$ & 0 & 0 \\
\hline Total. & $84^{*}$ & $69(82 \%)$ & $8(9.5 \%)$ & $7(8.5 \%)$ \\
\hline
\end{tabular}

* 4 patients with bilateral perforation, 2 blast injury, and 2 open hand slap. 
Table (3): Relation of site and size of perforation and healing

\begin{tabular}{|l|c|c|c|c||}
\hline \multicolumn{1}{|c|}{ Site of the perforation } & No.(\%) & Healed & Dry perforation & C.S.O.M \\
\hline \hline Posterior & $45(54 \%)$ & $41(91 \%)$ & $3(7 \%)$ & $1(2 \%)$ \\
\hline Anterior & $12(14 \%)$ & $11(92 \%)$ & $1(8 \%)$ & 0 \\
\hline Central(kidney shape) & $20(24 \%)$ & $17(85 \%)$ & $1(5 \%)$ & $2(10 \%)$ \\
\hline Sub total & $7(8 \%)$ & 0 & $3(43 \%)$ & $4(57 \%)$ \\
\hline Total & $84(100 \%)$ & $69(82 \%)$ & $8(9.5 \%)$ & $7(8.5 \%)$ \\
\hline
\end{tabular}

Table (4): Duration of healing of perforated tympanic membrane in relation to type of trauma

\begin{tabular}{|l|c|c|c|c|c|}
\hline \multicolumn{1}{|c|}{ Duration } & Total & $<2 \mathrm{Wk}$ & $2-4 \mathrm{Wk}$ & $5-6 \mathrm{Wk}$ & $>6 \mathrm{Wk}$ \\
\hline \hline Blast injury & 27 & $3(11 \%)$ & $9(33 \%)$ & $7(26 \%)$ & $8(30 \%)$ \\
\hline hand slap & 21 & $5(24 \%)$ & $12(57 \%)$ & $2(9.5 \%)$ & $2(9.5 \%)$ \\
\hline Foreign body & 8 & $3(37.5 \%)$ & $3(37.5 \%)$ & $2(25 \%)$ & 0 \\
\hline Ear syringing & 7 & 0 & $1(17 \%)$ & $4(50 \%)$ & $2(33 \%)$ \\
\hline Ear suction & 4 & 0 & $1(25 \%)$ & $2(50 \%)$ & $1(25 \%)$ \\
\hline $\begin{array}{l}\text { Fracture } \\
\text { temporal bone }\end{array}$ & 2 & 0 & $1(50 \%)$ & $1(50 \%)$ & 0 \\
\hline Total & 69 & $11(16 \%)$ & $27(39 \%)$ & $18(26 \%)$ & $13(19 \%)$ \\
\hline \hline
\end{tabular}

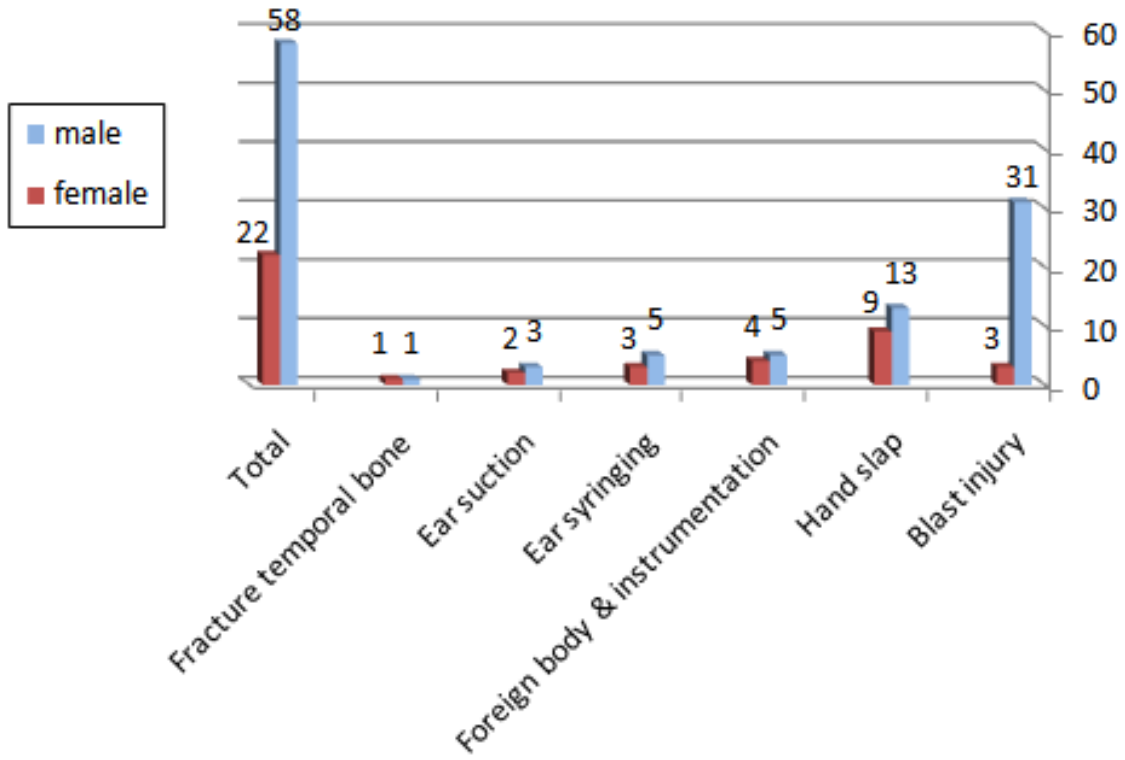

Fig (1): The relation of the sex with causes of traumatic perforation of the tympanic membrane 


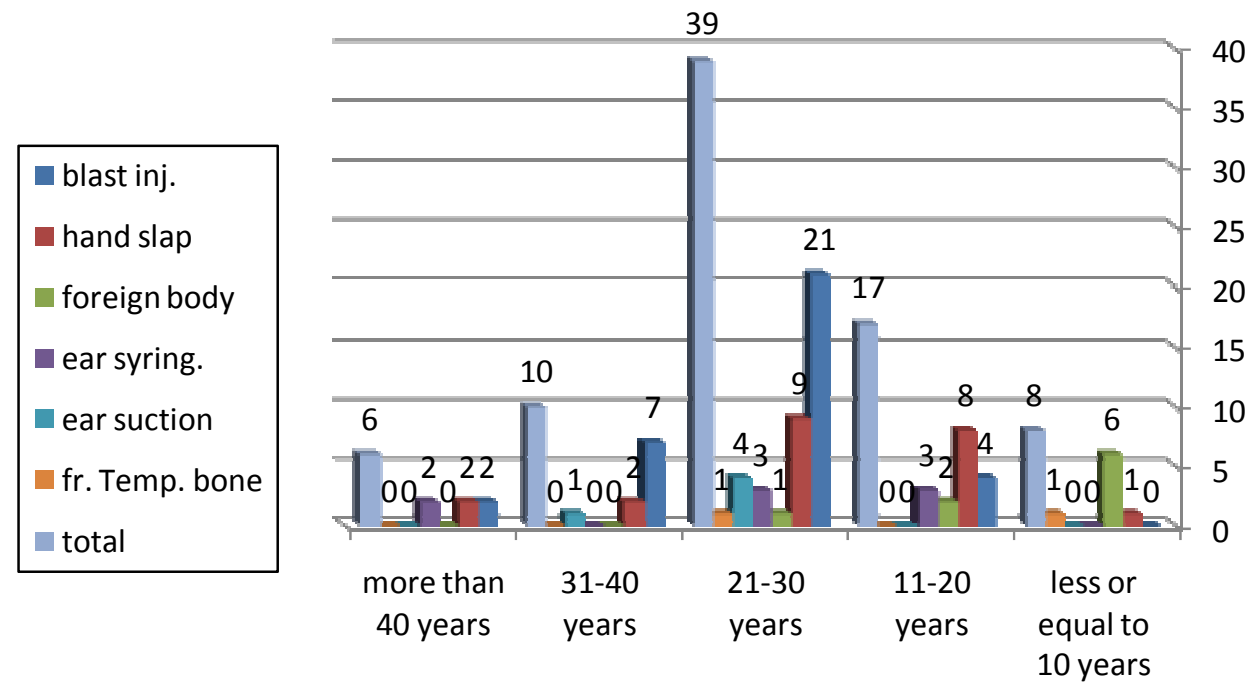

Fig (2): Relation of age with traumatic perforation of the tympanic membrane

\section{Discussion}

The perforation of the tympanic membrane heals by means of epithelial migration pattern of tympanic membrane, and external auditory canal which proceeds from umbo outward ${ }^{(5)(6)}$.

Following an acute injury, platelets gather to cause vasoconstriction and forming thrombus. An inflammatory response ensues, attracting neutrophils, macrophages, and bioactive cytokines to the wound. A matrix of proteoglycans and glycosaminoglycans is formed and allows proliferation of squamous epithelium layer of the tympanic membrane across the perforation forming a scaffold on which the mucosal layer can grow. The squamous elements responsible for bridging the perforation originate from 'up stream' and must traverse the length of the defect, so it is not surprising that the large perforations are associated with delayed healing and higher rate of chronicity ${ }^{(7)}$. In the experimental animals, proliferation of stratified squamous epithelium at the rim of a perforation begins within 12 hours, and granulation tissue growth begins at 36 hours $^{(8)}$. Regeneration of the epithelium of the inner (mucosal) surface is more sluggish and begins only after several days. As long as there is suitably flat surface, stratified squamous epithelium grows at the rate of $1 \mathrm{~mm}$ a day ${ }^{(9)}$. Mesothelial layer does not regenerate. So new tympanic membrane is thin and has two layers, with absence of middle fibrous layer $^{(6)}$.

Many studies concerning healing of traumatic tympanic membrane perforations were conducted. Griffen (1979) found $90 \%$ of traumatic tympanic membrane perforations heal spontaneously within three months after injury ${ }^{(3)}$. Kristensen. (1992), found that the spontaneous healing rate appeared to be $(78.7 \%)$ of traumatic tympanic membrane perforation of all sorts seen within 14 days after injury ${ }^{(10)}$. Chun, et al. (1999) reported spontaneous healing was $76 \%$, and the mean duration for complete healing was 22.1 days $^{(11)}$. Bobby (2006) showed that within one month $68 \%$ are healed and within three months $94 \%$ are healed. In our study ( $82 \%$ ) of healed traumatic perforation occurs within 6 weeks.

The blow to the ear and instrumentation injuries are the common causes of traumatic tympanic membrane perforation. In our study blast injury was the commonest cause, as it is usually seen during war and bombing, the condition of our country (Iraq); they were 34 cases $(43 \%)$. The tympanic membrane is the structure most frequently injured by blast, because even at low pressure 5 Psi (pound per square inch) can cause tympanic perforation $^{(12)}$, and the force required to 
rupture the tympanic membrane is equivalent to $195 \mathrm{~dB}^{(5)}$.

Temporary neuropraxia in the ear's receptor organs, manifested by deafness, tinnitus, and vertigo; if dynamic over pressure are high enough, the ossicles of middle ear can be dislocated ${ }^{(13)}$. Cholesteatoma formation and development of perilymph fistula are possible in blast injury ${ }^{(14)}$. Kronenberg, et al. (1993) evaluated healing in 147 patients with 200 perforated ear drums, following blast. Spontaneous healing occurred in 155 ears $(74 \%)$ in one year although $131(85 \%)$ of these healed within the first three months ${ }^{(15)}$. Our result for blast injuries, spontaneous healing was 27 cases $(75 \%)$, which is the lower rate of healing in relation to other causes, because some are large perforations (subtotal perforation) (Table 3), or get infection because of contamination by blast wind, especially those victims who were close to the explosion, and all were having shell wounds in their bodies.

Open hand slap generally the second cause and main cause in women, due to the rise in domestic violence ${ }^{(2)}$ and child abuse, but in our study the male becomes a victim of American military, and security officers. There were 13 males (59\%), two of them had bilateral perforation, and 9 cases $(41 \%)$ were females (Figure 1). Usually it carries better prognosis than blast injury, because of less infection rate, and moderate size perforations, $81 \%$ of healed cases occurred within 4 weeks (Table 4).

Traumatic tympanic membrane perforations due to ear syringing and ear suction, usually get infection (otitis media or otitis externa like otomycosis). They usually delay healing process, and once the infection has resolved most perforations healed spontaneously ${ }^{(16)}$, except large perforation. All cases (seven) with subtotal perforation did not heal spontaneously during at least 6 months' follow up.

The type of trauma, the alkaline battery on contact with moisture results in liquefaction necrosis which leads to much more extensive injury; over time causes TMP, exposure of bone of the ear canal, ossicular destruction, sensory neural hearing loss, and facial palsy, so it should be removed as soon as possible ${ }^{(17)}$. Likewise, slag burns tend to cauterize the vasculature and healing incompletely ${ }^{(4)}$.

The prognosis of spontaneous healing is poorer with persistent Eustachian tube dysfunction, and chronic infections, because they weaken the tympanic membrane and impair healing ${ }^{(4)}$, so prevention and promptly treating ear infection hasten healing. It is imperative to give antibiotics at presentation to prevent a permanent perforation ${ }^{(10)}$. Checking for chronic nose and sinus problems, and treating them, if there is no healing ${ }^{(16)}$. The patients that healed after 6 weeks were (15) patients; all having otitis media during follow up period.

Histological examination of permanent perforation showed that stratified squamous epithelium grows medially over the edge of the perforation ${ }^{(18)}$ which appears to arrest the subsequent closure of the perforation. The removal of the medialized epithelium forms basis of some treatment of tympanic membrane perforation ${ }^{(19)}$, as it will not heal spontaneously. However, not all people with unhealed perforation need treatment, many people have small permanent perforation with no symptoms or significant hearing loss ${ }^{(20)}$.

\section{Conclusion}

Conservative care for traumatic perforation of the tympanic membrane gives excellent chance of spontaneous healing. The factors affecting the spontaneous healing include large size perforations, ear infections, type of trauma, and Eustachian tube dysfunction.

\section{References}

1. Carol A. Turkington. Perforated ear drum Health Article. Gale Encyclopedia of Medicine, 2002.

2. Francis B. et al. Trauma to the middle and inner ear: Grands Round Presentation, UTMB, Dept, of otolaryngology. October 23.2002.

3. Griffen WL Jr. A retrospective study of tympanic membrane perforation in a clinical practice. Laryngoscope 1979;89:261-82. 
4. Michael C. Ott, MD; Tympanic membrane perforation in adults. Postgraduate medicine. VoL 110.No 5, Nov.2001

5. Spiros Manolidis MD. Closure of tympanic membrane perforation. GlasscockShambaugh Surgery of the ear. BC Decker Inc.15 ${ }^{\text {th }}$ Edition.2003.P400-418.

6. Douglas M. Sorensen, M.D. Diseases of the external ear and tympanic membrane. ENT secrets, Bruce W. Jafek, MD. Jaypee Brothers. First Indian edition.1996.P34-39.

7. Blevins NJ, Karmody CS. Chronic myringitis: prevalence, presentation and natural history. Otol Neurootol 2001;22:310.

8. Taylor M. Healing of experimental perforation of tympanic membrane.J Laryngol Otol. 1965:79:140.

9. Gladstone HB, Jackler RK. Tympanic membrane wound healing. An overview. Otolaryngol Clin North Am .1995; 28:913932.

10. Kristensen S. Spontaneous healing of traumatic TMP in man. Century of experience. J Laryngol Otol 1992;106:1037-50.

11. Chun SH, Lee DW, Shin JK. A clinical study of traumatic tympanic membrane perforations. Korean J Otolaryngol Head Neck Surgery.1999 Apr. 42(4):437-441.

12. Patterson JH. Hamernik RP. Blast over pressure induced structural and functional changes in the auditory system. Toxicology 1997;121:29-40.
13. Deguine C, Pulec JL. Traumatic dislocation of the incus. Ear Nose Throat J.1995;74:800.

14. Mrena R, Back L, et al. Otologic consequences of blast exposure .Acta Otolaryngol.2004;124:946-952.

15. Kronenberg J, Ben-shosand J, Wolf $M$. Perforated tympanic membrane rupture after blast injury. Am J Otol 1993;14(1):924.

16. William B. Hurst. Out come of 22 cases of perforated tympanic membrane caused by otomycosis. The Journal of Laryngology \& otology (2001),115:879-880.

17. Mitchell K. Ballenger's otorhinolaryngology Head \& Neck Surgery. Chapter 14. Trauma to the middle ear. inner ear, and temporal bone. $16^{\text {th }}$ Edition. 2003. P345-356.

18. Somers T, et al. Growth factors in tympanic membrane perforation. Am J Otol 1998;19:428-34.

19. Yamashita T. Histology of tympanic perforation and replacement membrane. Acta Otolaryngol (stock) 1985;100:66-71.

20. www.privatehealth.co.UK/ diseases/ earnose - throat/perforated-ear drum. 